\title{
Chemical composition and antioxidant activity of essential oil of Cymbopogon flexuosus
}

\begin{abstract}
Anju Bhatnagar
Department of Chemistry, D.B.S. (P.G.) College Dehradun-248001(Uttarakhand), India

E-mail: anju_bhatnagar_2007@yahoo.com

Abstract

Cymbopogon species from the Poaceae family are widely distributed in the Himalayan region of India and commonly used as flavors, fragrances, cosmetics, and pharmaceuticals. It is known to contain compound citral, which give the lemon scent to many of the plants of the cymbopogon genera. The essential oil of Cymbopogon flexuosus has high polyphenolic content which is responsible for antioxidant properties. Beside citral is also used for the synthesis of vitamin B and lonones. The bioactive potential of Lemongrass and constituent are rapidly increasing which is reflected from growing number of reports being published. The present study was to know the chemical composition and in vitro antioxidant activity of essential oil of $C$. flexuosus from Uttarakhand. The essential oils of Cymbopogon collected in the region of Uttarakhand were obtained by hydrodistillation of the leaves and analyzed for chemical composition by GC/MS. The antioxidant activity of essential oils at different concentrations was determined against DPPH radical activity and vitamin $\mathrm{C}$ as the standard antioxidant compound. The $\mathrm{IC}_{50}$ value and percentage of DPPH inhibition were recorded. Twenty-five compounds were identified in essential oil extracted from leaves representing $93.15 \%$ of the oil composition. The yield of essential oil of Cymbopogon was $0.6 \pm 0.1 \%$ and the major compound in the essential oil was citral (a racemic mixture of two isoforms geranial and nearl) followed by heptenone $(1.98 \%)$, linalool $(1.65 \%)$, geraniol $(1.47 \%), \beta$-caryophyllene $(1.14 \%)$, limonene $(0.92 \%)$, nearl acetate $(0.82 \%)$, citronellal $(0.44 \%)$ and citronellol $(0.22 \%)$. Radical scavenging capacity (Inhibition, \%) of the C. flexuosus essential oil was high $(78.19 \pm 1.11)$ at the concentration level of $150 \mu \mathrm{g} / \mathrm{ml}$ and $I_{50}$ value of the essential oil was $43.67 \mu \mathrm{g} / \mathrm{ml}$. The data of this study encourages to consider the essential oil of $C$. flexuosus as a source of bioactive compounds which may add great industrial value to this crop.
\end{abstract}

Keywords: Cymbopogon flexuosus, Bioactivities, Antioxidant activity, Citral, Monoterpene

\section{INTRODUCTION}

The genus Cymbopogon family Poaceae is known for their essential oils of immense commercial significance in flavors, fragrances, perfumery and pharmaceuticals (Ganjewala,2009). Cymbopogon contain about 140 species worldwide, out of which 45 species are occur in India. The members of the genus Cymbopogon occur abundantly from mountains and grassland to arid zones in tropics and sub tropic regions of Asia, Africa, and America. (Bor, 1960; Soenarko, 1997). Cymbopogon species show large variation in morphological features and composition of essential oil at inter and intra specific level over the years. The prevalent economic species viz., $C$. flexuosus, $C$. citrates, $C$. winterianus, C. martini var. motia and sofia, C. nardus var. nardus, , C. pendulus, C. warancusa, C. khasianus. The essential oil, such as palmarosa oil, lemongrass oil, citronella oil, ginger grass

\section{Article Info}

https://doi.org/

10.31018/jans.v12i1.2207

Received: December 25, 2019

Revised: February 23, 2020

Accepted: March 3, 2020

\section{How to Cite}

Bhatnagar, A. et al. (2020). Chemical composition and antioxidant activity of essential oil of Cymbopogon flexuosus. Journal of Applied and Natural Science, 12(1): 25 - 29 https://doi.org/ 10.31018/jans.v12i1.2207 
ellal. Another terpenoid such as citral is used in ionone synthesis and vitamin A . (Khanuja et al., 2005).

Cymbopogon flexuosus is a perennial, tall, fast growing grass of $1.5 \mathrm{~m}$ long having lemon like smell. It has distinct, dark green foliage and also produces seed. Lemongrass mainly prefers tropical and subtropical climate, it grows well at a temperature between of $10^{\circ} \mathrm{C}$ to $33^{\circ} \mathrm{C}$ and needs enough sunshine for the development of oil in the plant. The grass is sensitive to cold weather and cannot withstand frost. The oil is extracted from fresh plant material mainly stalks and leaves of plant, by hydrodistillation method (Lawrence, 1988).

In recent years medicinal and pharmacological significance of lemongrass EO and its major constituent citral has been rapidly increased. A number of studies have revealed many useful bioactivities such as antimicrobial, allelopathic, anthelmintic, anti-inflammatory, anticancer, antioxidant, insect and mosquito repellent of lemongrass extract, oil, citral, and citral derived compounds. The goal of this study was to investigate the chemical composition and antioxidant activity of essential oil of C. flexuosus collected in the northern plain of Uttarakhand.

\section{MATERIALS AND METHODS}

Plant material: The aerial parts of $C$. flexuosus were collected from cultivated crops at experimental field of CAP Research Center, Dehradun in September 2016 and duly identified by Botany Department, Forest Research Institute, Dehradun. The location of experimental site is at an altitude of $30 \mathrm{~N}$, longitude of $78.03 \mathrm{E}$ and it experiences climate with hot and dry summer and chilled winter. After identification, the all sample were kept in the herbarium of D.B.S. (P.G.) College Dehradun, Uttarakhand (India).

Extraction of essential oil: The fresh leaves of $100 \mathrm{gm}$ was used to extract the oil by hydrodistillation method in 3 replicates by using Clevenger apparatus. The evaporated essential oil is collected as oil drop after condensation into a closed tube attached to Clevenger apparatus. Aqueous layer was separated from the essential oil with the help of separating funnel. The essential oil was dried over anhydrous $\mathrm{Na}_{2} \mathrm{SO}_{4}$ and stored in sealed vials under refrigeration prior to analysis. Oil content was calculated in terms of oil percentage as the mean of 3 samples. The fresh weight of the material was used to calculated the oil yield on the basis of $(\mathrm{v} / \mathrm{w})($ Kulkarni, et.al., 2003)

GC-MS analysis: It is performed using an Perkin Elmer Clarus 500 Gas Chromatograph interfaced with Perkin Elmer Clarus 500 mass spectrometer fitted with an RTX-5 capillary columns $(60 \mathrm{~m} \times$ $0.32 \mathrm{~mm}$ i.d., film thickness $0.25 \mu \mathrm{m}$ ). The range of oven column temperature is $60^{\circ} \mathrm{C}-210^{\circ} \mathrm{C}$, programmed at flow rate is $3^{\circ} \mathrm{C} / \mathrm{min}$, with $2 \mathrm{~min}$ is hold time, Helium using as carrier gas at $10 \mathrm{psi}$ constant pressure, 1: 50 is a split ratio, an injection volume was $0.02 \mu \mathrm{L}$ neat, injector, transfer line, source temperatures were $210^{\circ} \mathrm{C}$; ionization energy $70 \mathrm{eV}$; mass scan range $40-450 \mathrm{~m} / \mathrm{z}$. The Identification of constituents was done on the basis of retention time. The Retention Index [RI, calculated with reference to n-alkanes and its homologous series $\left(\mathrm{C}_{9}-\mathrm{C}_{26}\right.$, Polyscience Corp., Niles IL) under identical experimental condition], co-injection with standards (Aldrich and Fluka), mass spectra library search (NIST/EPA/NIH version 2.1 and Wiley registry of mass spectral data 7 th edition) and by comparing with the mass spectral literature database (Adams,1995; Davies, 1990). The relative quantities of individual components were calculated based on peak areas without using correction factors.

Antioxidant activity

Radical scavenging activity by DPPH: DPPH (2,2 -diphenyl -1-picryl hydrazyl) radical scavenging activity was measured with the Akter (2010) method. For each determination, stock solution $(1 \mathrm{mg} / \mathrm{ml})$ was diluted to a dilution series $(50 \mu \mathrm{g}$ $1000 \mu \mathrm{g} / \mathrm{ml}$ )with $60 \%(\mathrm{~V} / \mathrm{V})$ ethanol. A methanolic solution of DPPH $(5 \mathrm{ml}, 0.06 \mathrm{mM})$ was mixed in an aliquot of each dilution $(0.5 \mathrm{ml})$. The mixture was vigorously shaken and kept in the incubator for 30 $\mathrm{Min}$ at $37^{\circ} \mathrm{C}$. A control was run, containing $60 \%(\mathrm{v} /$ v) ethanol $(0.5 \mathrm{ml})$ and methanolic solution of DPPH ( $5 \mathrm{ml}, 0.06 \mathrm{mM}$ ). The absorbance of methanol as blank was measured at $517 \mathrm{~nm}$. The percentage of DPPH scavenging was calculated as follows:

DPPH radical scavenging activity $(\%)=\{$ (Abs control-Abs sample)/Abs control $\} \times 100 \quad \ldots .$. .Eq. 1

A graph was plotted between scavenging percentage of DPPH and different concentration of samples. The concentration of the sample necessary to decrease the DPPH concentration by $50 \%$ was obtained by interpolation from linear regression analysis and denoted $\mathrm{IC}_{50}$ value $(\mu \mathrm{g} / \mathrm{ml})$. All determinations were taken in triplicate. Data were expressed as means $\pm S D$. Ascorbic acid was used as reference compound.

$\boldsymbol{\beta}$-Carotene bleaching assay: To know lipid peroxidation activity of the samples, $\beta$-carotene bleaching assay was performed by Geckil et al. method. Crystalline $\beta$-carotene $(0.02 \mathrm{mg}$ ) was dissolved in chloroform $(10 \mathrm{ml})$ and then added linoleic acid $(20 \mathrm{mg})$ and $200 \mathrm{mg}$ of Tween 80 reagent. After removal of Chloroform by rotary evaporator under vacuum at $40^{\circ} \mathrm{C}$ for $5 \mathrm{~min}, 50 \mathrm{ml}$ of distilled water was added with vigorous stirring to form an emulsion. Add $0.1 \mathrm{ml}$ of essential oil extract $(1 \mathrm{ug} / \mathrm{ml})$ in $5 \mathrm{ml}$ of this emulsion. BHT was taken as standard. The test tube containing standard and sample were kept in water bath in Incuba- 
tor at $50^{\circ} \mathrm{C}$ and record the absorbance at an interval of 20 min till $2 \mathrm{hrs}$.

\section{RESULTS AND DISCUSSION}

The essential oil of aerial parts of $C$. flexuosus viz. , Krishna cultivated Dehradun, a Tarai area of Uttarakhand, isolated by hydrodistillation indicated that the essential oil yield was $0.6 \pm 0.1 \%$ on dry weight. Table -1 showed that twenty-five volatile constituents, representing $93.58 \%$ of the total composition in the essential oil. The most abundant components found in the essential oil were citral $\{\mathrm{a}$ isomeric mixture of geranial $(40.29 \%)$ and neral $(34.29 \%)\}$, followed by Geraniol $(1.47 \%)$, Linalool $(1.65 \%)$, Limonene $(0.92 \%), \beta-$ Caryophyllene (1.14\%), Neryl acetate $(0.82 \%)$,camphene $(2.01 \%)$, borneol $(1.01 \%)$, and Caryophyllene oxide $(1.10 \%)$ as a major constituents. The minor constituents were citronellal $(0.44 \%)$, a-terpineol $(0.35 \%)$, $\beta$-myrcene $(0.42 \%)$, Citronellol $(0.22 \%)$ and $\gamma$-cadinene $(0.62 \%)$ These results agree with those reported by Negrelle and Gomes (2007). Adukwuallen and Phillipa (2012) informed that citral was the main component in C.flexuosus and C.nardus. The Essential Oil of lemongrass has been investigated for chemical compositions ( Sharma et al., 1999; Khanuja et al., 2005; Ganjewala et al., 2009Padalia, et al.,

Table 1. Chemical composition of essential oil of $C$. flexuosus harvested in September from Uttarakhand.

\begin{tabular}{|c|c|c|c|}
\hline S.N. & $\begin{array}{l}\text { Retention } \\
\text { Index }\end{array}$ & $\begin{array}{l}\text { Name of constitu- } \\
\text { ents }\end{array}$ & $\begin{array}{l}\text { Area } \\
\%\end{array}$ \\
\hline 1 & 942 & $\alpha-P i n e n e$ & 0.74 \\
\hline 2 & 1160 & $\beta$-myrcene & 0.42 \\
\hline 3 & 956 & Camphene & 2.01 \\
\hline 4 & 931 & Hept-5-en-2 one & 1.98 \\
\hline 5 & 1034 & Limonene & 0.92 \\
\hline 6 & 1036 & $\beta$-ocimene & 0.05 \\
\hline 7 & 942 & $\alpha-P i n e n e$ & 0.63 \\
\hline 8 & 1225.8 & Carven & 0.14 \\
\hline 9 & 668 & Pentyl propyl ketone & 1.29 \\
\hline 10 & 1154 & Citronellal & 0.44 \\
\hline 11 & 1098 & Linalool & 1.65 \\
\hline 12 & 1109 & Borneol & 1.01 \\
\hline 13 & 1148 & Verbenol & 1.07 \\
\hline 14 & 1191 & a-terpineol & 0.35 \\
\hline 15 & 1210 & Mentha & 0.44 \\
\hline 16 & 1241 & Neral & 34.29 \\
\hline 17 & 1257 & Geraniol & 1.47 \\
\hline 18 & 1270 & Geranial & 40.29 \\
\hline 19 & 1359 & Neryl acetate & 0.82 \\
\hline 20 & 1418 & $\beta$-Caryophyllene & 1.14 \\
\hline 21 & 1429 & Isoeugenol & 0.01 \\
\hline 22 & 1226 & Citronellol & 0.22 \\
\hline 23 & 1514 & Y-Cadinene & 0.62 \\
\hline 24 & 1229 & Nerol & 0.05 \\
\hline \multirow[t]{2}{*}{25} & 1584 & Caryophyllene oxide & 1.10 \\
\hline & & Oil content $(\%)^{*}$ & 93.15 \\
\hline
\end{tabular}

2011, Bhatnagar, 2018).

The major component of the essential oil of the herbal plant are mainly comprised with monoterpenes, sesquiterpenes, and their oxygenated derivatives. These compounds are also known to exhibit diverse biological activities. It is described in an article of Mata et al., 2007, that geraniol and eugenol are known for their antioxidant activity. Most of the bioactivities of lemongrass oil has been attributed to its one or more major chemical constituents namely citral and geraniol (Gangwala, 2009).

Retention time was determined by GC-MS on a RTX - 5 capillary columns.

Retention Index determined with homologous series of n-alkanes $\left(\mathrm{C}_{9}-\mathrm{C}_{26}\right)$.

Some of the important bioactivities of citral are antimicrobial, antiviral, anti-inflammatory, allelopathic, antiparasitic and cognitive activities. Other oil constituents, such as limonene and borneol has immune-stimulatory, analgesic and anesthetic properties whereas geraniol, geranyl acetate and bisabolol possess different types of bioactivities such as antimicrobial, antifungal, antiinflammatory, anticancer and antioxidant (Padalia, et al., 2011; Ganjewala, 2009).

Antioxidant activity of $\boldsymbol{C}$. flexuosus: The free radical scavenging activity of $C$. flexuosus oil was measured by DPPH method is given in Table 2 . To evaluate the anti oxidative activities in a relatively short time, the model of scavenging stable DPPH free radicals can be used. The absorbance value decreases as radical is scavenged through a donation of hydrogen by antioxidants to form the stable DPPH-H molecule, due to this color change from purple to yellow. The effect of antioxidants on $\mathrm{DPPH}$ radical scavenging activity was thought to be due to their hydrogen donating ability. In aromatic plants, antioxidant activity of essential oil is mainly attributed to the active compounds present in them. This activity can be due to the high amount of main constituents, but also to the presence of other constituents in small quantities or synergy among them. In this study, the antioxidant activity of essential oil was compared with Vitamin $C$ as a reference antioxidant compound, determined by the method of DPPH radical scavenging assay and the results are summarized in Table 2. It was found that the essential oil $C$. flexuous showed similar antioxidant capacities as compared to vitamin C (Standard antioxidant compound). The results indicated that the radical scavenging activity (\%inhibition) of the essential oil from Cymbopogon flexuous was highest $(78.19+1.11)$ at the concentration of $150 \mu \mathrm{g} / \mathrm{ml}$, Table 2 . It was noticed that the scavenging activity of the essential oil was increased with increase the oils concentrations. The results clearly indicate that essential oil of lemongrass is effective in scavenging free radical and has the potential to be a powerful antioxidant. 
Table 2. Scavenging effect (\%) of essential oil of $C$. flexuosus as well as vitamin $C$ on DPPH at different concentrations.

\begin{tabular}{|c|c|c|c|c|}
\hline S.N. & & Concentration (ug/ml) & $\%$ Inhibition of DPPH & $\mathrm{IC}_{50}(\mathrm{ug} / \mathrm{ml})$ \\
\hline 1. & Essential oil & 10 & $30.01 \pm 1.00$ & 43.67 \\
\hline 2 & & 20 & $40.27 \pm 0.11$ & \\
\hline 3 & & 40 & $56.01 \pm 0.89$ & \\
\hline 4 & & 60 & $60.11 \pm 0.21$ & \\
\hline 5 & & 100 & $71.02 \pm 1.02$ & \\
\hline 6. & & 150 & $78.19 \pm 1.11$ & \\
\hline 7 & & 10 & $31.01 \pm 0.35$ & 36.32 \\
\hline 8 & Vitamin C & 20 & $51.11 \pm 0.11$ & \\
\hline 9 & & 40 & $70.02 \pm 0.15$ & \\
\hline 10 & & 60 & $80.57 \pm 0.79$ & \\
\hline 11 & & 100 & $85.21 \pm 0.15$ & \\
\hline 12 & & 150 & $90.03+1.88$ & \\
\hline
\end{tabular}

$\beta$-Carotene bleaching activity of $\mathrm{C}$. flexuous: The $\beta$-Carotene anti-bleaching activity of sample was measured by monitoring the color intensity of emulsion at $470 \mathrm{~nm}$ for every $15 \mathrm{~min}$ for $2 \mathrm{hrs}$. The concentration was taken to be $1 \mu \mathrm{g} / \mathrm{ml}$. The initial concentration was considered to be $100 \%$. In the first 15 minutes the sample showed 94.56 $\%$ effect and $84 \%$ of the effect shown by standard. In one hour of incubation, percentage decrease was found to be $72.18 \%$. The decrease of standard percentage is $54.7 \%$ in one hour time. By the end of second hour the percentage decrease was $60.2 \%$ and $28.2 \%$ for oil and standard respectively. Reena et. al., 2015; reported that In vitro antioxidant activity of lemongrass essential oil by using $\mathrm{DPPH}$ assay is $0.5 \mathrm{mg} / \mathrm{ml}$ and $\beta$-Carotene bleaching is $84.1 \%$ bleaching in $I^{\text {st }}$ hour and went to $46.8 \%$ by the completion of $2^{\text {nd }}$ hour which is relatively similar in comparison of $C$. flexuosus.

\section{Conclusion}

The GC-MS analysis identified twenty-five volatile compounds in the essential oil of $C$. flexuosus. The essential oil composition was mainly constituted of monoterpene fractions with a large proportion of citral and geraniol. Citronellal, $\beta-$ Caryophyllene, camphene, limonene, neryl acetate, borneol and caryophyllene oxide as minor constituents. The free radial scavenging activity of essential oil of C.flexuosus through its ability to quench the synthetic DPPH radical and betacarotene bleaching method showed that essential oil of $C$. flexuosus had a good antioxidant capacity compared with Standard antioxidant compound. Thus, C. flexuosus can be used as an easily accessible source of natural antioxidants.

\section{ACKNOWLEDGEMENTS}

This work was supported by UGC, New Delhi, India under the Minor Research Project Grant. Also, I duly acknowledge the CIMAP-CSIR research center, Pantnagar, Uttarakhand, India for providing necessary facilities and support.

\section{REFERENCES}

1. Adams R.P. (1995). Identification of Essential Oil Constituents by Gas Chromatography/Mass Spectroscopy. Allured Publ. Corp., Carol Stream, Illinois.

2. Adukwu, E.C., Alllen, S.C.H., and Phillips, C.A., (2012) The anti-biofilm activity of lemongrass (Cymbopogon flexuosus) and grapefruit (Citrus paradise) essential oils against five strains of Staphylococcus aureus, Journal of Applied Microbiology, 113, 1217-1227.

3. Akter, S., Ahmed, M., Eun, J.B.,(2010). Solvent effect on antioxidant properties of persimmon (Diospyros Kaki L.Cu. Daebong) Studs. Int. J. Food Sci. Tech., 45, 2258-2264.

4. Bhatnagar, A, (2018). Composition variation of essential oil of cymbopogon spp. Growing in Garhwal region of Uttarakhand, India, Journal of Applied and Natural science, 10(1): 363-366.

5. Bor, N.L., (1960). The Grasses of Burma, Ceylon, India, and Pakistan, Pergamon Press, London, pp. 767.

6. Davies D.W. (1990). Gas chromatographic retention indices of monoterpenes and sesquiterpenes on methyl silicone and Carbowax 20M phases, J. Chromatograph., 503, 1-24.

7. Ganjewala, D., (2009) Cymbopogon essential oil: chemical compositions and bioactivities, International Journal of essential oil therapeutics, 3, 56-65.

8. Ganjewala, D. and Gupta, A.K (2013), Lemongrass (Cymbopogon flexuous steud.) wats essential oil: overview and biological activities, RPMP Vol. 37: essential oil-II, 233-274.

9. Geckil H, Ates B, Durmaz G, Erdogan S. Yilmaz I. (2005). Antioxidant, free radical scavenging and Metal chelating characteristic of Propilis. American J. of Biochemistry and Biotechnology. 1:27-31.

10.Gupta, B.K. and Daniel, P. (1982). Aromatic grasses of India and their utilization: A plea for further research, Pafai J. 4, 13-27.

11.Gupta, B.K. and Jain, N. (1978). Cultivation and utilization of genus Aromatic Cymbopogon in India, Indian Perfume. 22, 55-68.

12.Khanuja, S.P.S; Shasany, A.K., Pawar, A., Lal, R.K. (2005). Essential oil constituents and RAPD markers to establish species relationship in Cymbopogon Spreng. (Poaceae), Biochem. Syst. Ecol. 33, 171186.

13.Kulkarni, R.N.., Baskaran, K . and Ramesh S. (2003). Five cycles of recurrent selection for increased es- 
sential oil content in East Indian Lemongrass: Response to selection, and effects on heritabilities of traits and inter trait correlation, Plant Breed. 122:131135.

14.Lawrence B.M. (1988). Progress in essential oil: citronella oil,Perfum. Flav. 23, 80-82.

15.Mata, A.T., Proenca, C., Ferreira, A. R., Serralheiro, M.L.M., Nogueira, J.M.F and Noqueira, J. M.F and Araujo, M.E.M,(2007), Antioxidant and antiacetylcholinesterase activities of five plants used as Portuguese food species. Food Chemistry, 103:778-786.

16.Negrelle,R.R.B., and Gomes,E.C.,(2007) Cymbopogon citrates (DC.) stapf chemical compostion and biological activities. RevistaBrasileira de PlantasMedicinaisBotucatu (Brasil), 9(1) 80-92.

17.Padalia, R.C., verma.R.S., Chanotiya,C.S ., Yadav, $A,(2011)$. The chemical fingerprint of the fragrant volatiles of Nineteen Indian Cultivars of Cymbopogon Spreng.5:4, 290-99.

18.Lawrence, R; Lawrence K.; Srivastave R., and Gupta, Deeti (2015), Antioxdant activity of lemon grass essential oil grown in North Indian plains. PThe scientific temper, IV; 23-29.

19.Sangwan, N.S., Yadav, U and Sangwan, R.S., (2001), Molecular analysis of genetic diversity in elite Indian cultivars of essential oil trade types of aromatic grasses (Cymbopogon species). Plant Cell Rep., 20; 437-444.

20.Soenarko, S. (1997). The genus Cymbopogon. Reinwardtia 9, 225-226.

21.Sharma, K.K., Nath, S.C. and Leclercq, P. A. (1999). The essential oil of a variant of Cymbopogon flexuosus (Nees ex Steud.) Wats from Northeast India, J. Essential Oil Res., 11:381-385. 